\title{
Menerapkan Budaya Keselamatan Pasien di Rumah Sakit
}

\author{
Mahdalena Br Surbakti
}

\section{Email : magdalenakurus15@gmail.com}

\begin{abstract}
Ethical problems in the hospital world are like the iceberg phenomenon. In Indonesia, there are many unresolved problems. Starting from cases of suspected malpractice, negligence in handling patients, discrimination against patients, to other crimes. Medical personnel have an important role in creating quality health services. Among them in implementing a patient safety culture. Currently patient safety has not fully become a culture in health services. This can be seen from the existence of cases such as malpractice, discrimination, and others. Every health profession has its own code of ethics. The existence of a code of ethics should be an aspect of implementing a patient safety culture. Patient safety is an important part of nursing services that can improve safety culture thereby reducing the impact of incidents on patients. The impact that occurs due to the hospital not implementing patient safety can decrease the quality of hospital services so that the accreditation level will decrease. Building a patient safety culture is an important element to improve patient safety and quality of care.
\end{abstract}

Keywords: Patient safety culture, hospital, health workers

\begin{abstract}
Abstrak
Permasalahan etik didunia rumah sakit seperti halnya fenomena gunung es. Di lndonesia banyak permasalahan yang tidak terungkap. Mulai dari kasus dugaan malpraktik, kelalaian dalam penanganan pasien, diskriminasi terhadap pasien, sampai tindak kriminal lainnya. Tenaga medis memiliki peran penting dalam menciptakan pelayanan kesehatan yang bermutu. Di antaranya dalam menerapkan budaya keselamatan pasien. Saat ini keselamatan pasien belum sepenuhnya menjadi budaya dalam pelayanan kesehatan. Hal ini terlihat dari masih adanya kasus seperti malpraktik, diskriminasi, dan lainnya. Setiap profesi kesehatan memiliki kode etik masing-masing. Keberadaan kode etik seharusnya menjadi aspek dalam penerapan budaya keselamatan pasien. Patient safety menjadi bagian penting dalam pelayanan keperawatan yang dapat meningkatkan budaya keselamatan sehingga mengurangi dampak terjadinya insiden terhadap pasien. Dampak yang terjadi akibat rumah sakit tidak
\end{abstract}


menerapkan patient safety dapat terjadi penurunan mutu pelayanan rumah sakit sehingga tingkat akreditasi akan menjadi penurunan. Membangun budaya keselamatan pasien merupakan elemen penting untuk meningkatkan keselamatan pasien dan kualitas pelayanan. Kata Kunci : Budaya keselamatan pasien, rumah sakit, petugas kesehatan

\section{Latar Belakang}

Rumah sakit sebagai organisasi badan usaha di bidang kesehatan mempunyai peranan penting dalam mewujudkan derajat kesehatan masyarakat secara optimal. Oleh karena itu rumah sakit dituntut agar mampu mengelola kegiatannya dengan mengutamakan pada tanggung jawab para professional di bidang kesehatan, khususnya tenaga medis dan tenaga keperawatan dalam menjalankan tugas dan kewenangannya. Tidak selamanya layanan medis yang diberikan oleh tenaga kesehatan dapat memberikan hasil yang sebagaimana diharapkan semua pihak. Tenaga kesehatan yang melakukan kelalaian dapat dapat disebut melakukan malpraktik. Malpraktik yang dilakukan oleh tenaga kesehatan dapat berupa malpraktik dibidang medik dan malpraktik medik. Karena banyaknya kasus malpraktik, maka harus diterapkarr program keselamatan pasien (Patient Safety). Keselarnatan telah menjadi isu global termasuk juga untuk rumah saklt. Sejak Institute of Medicine di Amerika Serikat menerbitkan laporan yang mengagetkan banyak pihak "to error is human”, Building a Safer Health System.
Laporan itu mengemukakan penelitian di rumah sakit yang ada di Utah dan Colorado serta New York. Di Utah dan Colorado ditemukan KTD (Adverse Event) sebesar $2,9 \%$ yang $6,6 \%$ diantaranya meninggal. Di New York KTD adalah sebesar 3,7\% dengan angka kematian 13,6\%. Angka kematian akibat KTD pada pasien rawat inap di seluruh Amerika yang berjumlah 33,6 juta per tahun berkisar 44.000-98.000 per tahun. Publikasi WHO tahun 2004, mengumpulkan angka-angka penelitian rumah sakit di berbagai negara, yaitu Amerika, Inggris, Denmark, dan Australia, ditemukan KTD dengan rentang 3,2-16,6\%. Dengan data-data tersebut, berbagai negara segera melakukan penelitian dan mengembangkan Sistem Keselamatan Pasien.

Keselamatan pasien adalah prinsip dasar dalam pelayanan kesehatan. Menurut Depkes RI Keselamatan pasien (patient safety) rumah sakit adalah suatu sistem dimana rumah sakit membuat asuhan pasien lebih aman. Sistem tersebut meliputi: assessmen risiko, identifikasi dan pengelolaan hal yang berhubungan dengan risiko pasien, pelaporan dan analisis insiden, kemampuan belajar dari insiden 
dan tindaklanjutnya serta implementasi solusi untuk meminimalkan timbulnya risiko. Sistem tersebut diharapkan dapat mencegah terjadinya cedera yang disebabkan oleh kesalahan akibat melaksanakan suatu tindakan atau tidak melakukan tindakan yang seharusnya dilakukan.

\section{Metode}

Rancangan penelitian yang digunakan adalah literature review. Dengan melakukan analisis dan kajian bebas pada jurnal, e-book, maupun buku teks yang berkaitan dengan materi pembelajaran yaitu budaya pasien, yang mana keselamatan pasien ini sebagai prioritas utama dan juga dapat meningkatkan mutu pelayanan kesehatan. Jurnal atau artikel yang digunakan pada literature review ini adalah jurnal atau artikel yang didapatkam dari google scholar, google book, library usu pada 10 tahun terakhir penerbitan. Dalam mencari literature reviewnya, menggunakan kata budaya, keselamatan pasien, pelayanan kesehatan.

\section{Hasil}

Berdasarkan hasil penelitian dari literature review yang meliputi jurnal, teks book, dan e-book, didapatkan berbagai budaya keselamatan pasien yang nantinya dapat meningkatkan mutu pelayanan kesehatan. Pada literature review didapatkan hasil bahwa untuk meningkatkan kualitas dan kepuasan pasien terhadap pelayanan kesehatan, seorang perawat harus mampu menerapkan budaya keselamatan pasien. Keselamatan pasien adalah prioritas. Perawat harus lebih mengutamakan keselamatan pasien dengan cara kerjasama Tim agar nantinya penerapan keselamatan pasien ini menjadi budaya yang harus diterapkan di rumah sakit.

\section{Pembahasan}

Budaya keselamatan pasien merupakan pondasi utama menuju keselamatan pasien. Penerapan budaya keselamatan pasien adalah sesuatu yang mutlak yang harus diaplikasikan di rumah sakit agar mampu menurunkan KTD secara signifikan. Penelitian Brown \& Wolosin (2013) mencoba mengeksplorasi hubungan antara persepsi staf terhadap budaya keselamatan dan langkah-langkah yang sedang berlangsung di rumah sakit berdasarkan struktur unit keperawatan, proses perawatan, dan resiko yang merugikan pasien. Hubungan antara tindakan keperawatan, kinerja rumah sakit dan budaya keselamatan dieksplorasi di 9 rumah sakit California dan 37 unit keperawatan. Persepsi budaya keselamatan diukur 6 bulan sebelum pengumpulan metrik keperawatan dan hubungan antara kedua data yang dieksplorasi 
menggunakan hubungan korelasional dan analisis regresi. Hubungan signifikan yang ditemukan adalah langkah-langkah proses untuk pencegahan jatuh. Beberapa asosiasi diidentifikasi dari budaya keselamatan Budaya keselamatan pasien merupakan pondasi utama menuju keselamatan pasien. Penerapan budaya keselamatan pasien adalah sesuatu yang mutlak yang harus diaplikasikan di rumah sakit agar mampu menurunkan KTD secara signifikan. Penelitian Brown \& Wolosin (2013) mencoba mengeksplorasi hubungan antara persepsi staf terhadap budayakeselamatan dan langkah-langkah yang sedang berlangsung di rumah sakit berdasarkan struktur unit keperawatan, proses perawatan, dan resiko yang merugikan pasien. Hubungan antara tindakan keperawatan, kinerja rumah sakit dan budaya keselamatan dieksplorasi di 9 rumah sakit California dan 37 unit keperawatan. Persepsi budaya keselamatan diukur 6 bulan sebelum pengumpulan metrik keperawatan dan hubungan antara kedua data yang dieksplorasi menggunakan hubungan korelasional dan analisis regresi. Hubungan signifikan yang ditemukan adalah langkah-langkah proses untuk pencegahan jatuh. Beberapa asosiasi diidentifikasi dari budaya keselamatan.

Budaya keselamatan pasien merupakan kewajiban dan tanggung jawab seluruh pegawai. Pengawai adalah bagian dari organisasi merupakan ujung tombak dalam budaya keselamatan pasien (Amarapathy, Sridharan, Perera, \& Handa, 2013). Di samping itu organisasi rumah sakit sebagai pemberi pelayanan kesehatan harus mampu menerima keselamatan sebagai nilai baru dalam budaya organisasi dengan komitmen berani berubah, berubah dalam arti blaming cultur menjadi safety cultur (Cahyono, 2008). Budaya keselamatan pasien dikatakan berhasil apabila semua elemen yang ada didalam rumah sakit menerapkan budaya keselamatan pasien dalam pekerjaannya sehari-hari (Reiling, 2009). Sedangkan Beginta (2012) mengatakan bahwa upaya yang dapat. Dalam melaksanakan program patient safetlt, pihak manajemen rumah sakit sudah melakukan planning yang baik untuk menyusun program patient safety. meskipun perencanaan sudah dilaksanakan dengan liaik namun output dari program tersebut kurang maksimal. Dalam menjalankan fungsi manajernen, rnanajemen, seorang manajer diharapkan memiliki kemampuan yang cukup dalam mengorganisasikan pegawainya. Salah satu kemampuan yang dimaksud adalah kemampuan motivasi SDM yang ada. Manajer dan asisten keperawatan sebaiknya memberikan motivasi untuk menimbulkan dorongan kepada perawat. Dengan diberikannya motivasi, diharapkan perawat akan bersemangat dalam 
melaksanakan program patient safety. Tingkat pengetahuan tenaga medis khususnya perawat sangatlah penting dalam meiaksanakan asuhan keperawatan. Semakin tinggi pengetahuan perawat tentang kode etik dan hukum kesehatan maka semakin baik pula kinerja perawat dalam melaksanakan asuhan keperawatan. Untuk meningkatkan pengetahuan perawat mengenal kode etik dan hukum kesehatan maka perawat harus membaca buku mengenai kode etik keperawatan dan hukum kesehatan. Selain itu dapat juga melalui teknologi internet serta melalui teman seprofesinya. Upaya untuk menambahkan tingkat pengetahuan perawat atau tenaga kesehatan yang lain yaitu melalui pelatihan atau seminar pelatihan dan seminar dapat bermanfaat untuk melakukan evaluasi terhadap program dan standar-standar termasuk standar asuhan keperawatan standar asuhan keperawatan harus selalu ditinjau keakuratannya sehingga tidak terjadi suatu kesaiahan yang dapat merugikan pasien, selain itu perawat harus dibina untuk mencapai kinerja yang professional dan bertanggung jawab.

Dugaan malpraktek yang dilakukan petugas pelayanan kesehatan yang mengakibatkan pasien mengalami kerugian mulai dari materi, cacat fisik bahkan sampai meninggal dunia memperlihatkan masih rendahnya mutu pelayanan kesehatan di rumah sakit. Patient safety (keselamatan pasien) belum menjadi budaya yang harus diperhatikan oleh rumah sakit di Indonesia6. Tidak ada lagi alasan bagi setiap rumah sakit untuk tidak menerapkan budaya keselamatan pasien karena bukan hanya kerugian secara materi yang didapat tetapi juga ancaman terhadap hilangnya nyawa pasien. Menurut Najihah (2018) dengan melakukan pelaporan insiden keselamatan pasien dapat meningkatkan penerapan budaya keselamatan pasien sehingga insiden keselamatan pasien tersebut dapat dihindari. Namun masih banyak petugas kesehatan yang mengabaikan pelaporan insiden tersebut karena merasa insiden tersebut dapat ditangani sendiri dan hanya melaporkan apabila sudah terjadi cedera. Persepsi dari petugas kesehatan tentang budaya keselamatan pasien merupakan hasil dari proses kognitif yang selama ini diterapkan oleh petugas kesehatan dalam memberikan pelayanan kesehatan. Di RSUD dr Rasidin Padang dimensi persepsi ini adalah sebesar 57\% dengan kategori cukup. Hal ini menunjukkan bahwa selama ini tingkat pemahaman budaya keselamatan pasien dari petugas kesehatan sudah cukup, namun sebaiknya harus ditingkatkan lagi sehingga pelaksanaan program keselamatan pasien dilakukan secara maksimal. Hasil penelitian Hall et al (2004) mengatakan bahwa rendahnya 
jumlah perawat professional dan berpengalaman yang bekerja pada sebuah unit semakin tinggi juga jumlah insiden medical error. Banyaknya proporsi perawat professional dan berpengalaman akan menghasilkan pemahaman dan persepsi pada program keselamatan pasien yang baik sehingga dapat mencegah terjadinya insiden keselamatan pasien.

Sejatinya pelaporan insiden keselamatan pasien sangat dibutuhkan oleh semua pihak guna perbaikan pelayanan dalam hal ini khususnya asuhan keperawatan. Informasi dari pelaporan insiden keselamatan pasien yang akurat dan jelas dapat membantu identifikasi akar permasalahan bagaimana insiden tersebut bisa terjadi serta identifikasi faktor risiko sehingga insiden yang sama dapat dicegah untuk kemudian hari. Peran dan fungsi perawat yang salah satunya yaitu peran sebagai peneliti. Informasi yang benar dan jelas yang diperoleh dai sistem pelaporan, asesmen risiko, kajian insiden, dan audit serta analisis, digunakan untuk menentukan solusi. Indikator respon tidak menghukum terhadap kesalahan ini menunjukkan bahwa dimasa yang akan datang pelaporan terhadap insiden keselamatan pasien tidak semata-mata hanya berupa pelaporan insiden keselamatan, namun pelaporan tersebut hendaknya ditindaklanjuti guna memperbaiki kesalahan dan mencari akar permasalahan, tidak untuk menghukum perawat yang melakukan kesalahan atau berpengaruh terhadap penilainan kinerjanya. Ketika kesalahan dilaporkan, maka cukup melaporkan masalah sendiri dilaporkan menemukan jalan keluar tidak menunjukkan siapa pelaku harus dihukum. Belajar dari insiden keselamatan pasien hanya akan berhasil jika setiap permasalahan tidak dilihat sebagai kesalahan individu tetapi harus diperhatikan dengan pendekatan sistem dan pemahaman faktor manusia. Sebagaimana diatur dalam Peraturan Menteri Kesehatan Republik Indonesia nomer 755/Menkes/Per/IV/2011 tentang pelaksanaan komite medis di rumah sakit bahwa audit medis dilakukan dengan memprioritaskan semua staf untuk menghilangkan blaming (menyalahkan), naming (menyebut atau mencari siapa yang salah), dan shaming (mempermalukan atau mengakui kesalahan). Untuk mampu belajar dari kesalahan harus ditekankan pada upaya mencari apa yang salah, mengapa kesalahan tersebut dapat terjadi, dan apa yang bisa dilakukan untuk memperbaiki kesalahan. Staf yang adekuat juga menjadi faktor penentu dalam penerapan budaya keselamatan pasien. Kurangnya jumlah maupun kualitas tenaga perawatan berdampak pada tingginya beban kerja perawat yang merupakan faktor kontribusi 
terbesar sebagai penyebab human error dalam pelayanan keperawatan. Oleh karena itu, sangat direkomendasikan untuk meningkatkan jumlah staf yang adekuat untuk meningkatkan keselamatan pasien. Rumah sakit dengan staf keperawatan yang tidak memadai sangat berisiko untuk terjadi kesalahan yang berujung kepada terjadinya hal yang tidak diinginkan.

Menurut Bird (2005) dalam Hamdani(2007) manfaat budaya keselamatan pasien antara lain, adalah :

1. Organisasi lebih tahu jika ada kesalahan yang akan terjadi atau kesalahan tersebut telah terjadi.

2. Meningkatnya laporan kejadian yang dibuat dan belajar dari kesalahan yang terjadi akan berpotensial menurunnya kejadian sama yang terulang kembali dan keparahan dari keselamatan pasien.

3. Kesadaran akan keselamatan pasien, yaitu bekerja untuk mencegah kesalahan dan melaporkan jika ada kesalahan.

4. Berkurangnya perawat yang merasa tertekan, bersalah, malu akibat kesalahan yang diperbuat.

5. Berkurngnya turn over pasien, karena pasien yang mengalami insiden umumnya akan mengalam perpanjangan hari perawatan dan pengobatan.

6. Mengurangi biaya yang diakibatkan oleh kesalahan dan penambahan terapi.
7. Mengurangi sumber daya yang dibutuhkan dalam menangani keluhan pasien.

\section{Penutup}

Dalam mencapai pelayanan kesehatanyang berkualitas seorang tenaga kesehatan harus mampu menerapkan budaya keselamatan pasien agar terhindar dari kejadian tidak diinginkan. Selain itu pengetahuan dan komunikasi jugaberpengaruh terhadap terlaksananyapatient safety. Salah satu aspek yang penting dalam terlaksananya patient safety yaitu aspek etika. Etika sangatlah penting karena akan menyangkut tentang prosedur dalam melaksanakanasuhan keperawatan atau melaksanakan tugas dalam melayani kesehatan. Dalampelayanan kesehatan maka tenaga medis harus sesuai dengan kode etik dan hukum kesehatan. Hal ini untuk menghindari atau mengurangi praduga terjadinya malpraktik.

\section{Daftar Pustaka}

1.Buhari.,B,.(2019).Budaya Keselamatan Pasien Rumah Sakit Pemerintah Dan Rumah Sakit Swasta Di Kota Jambi.Jurnal Aisyiyah Medika.3(1).

2.Herawati.,Y.,T,.(2015).Budaya

Keselamatan Pasien Di Ruang Rawat Inap Rumah Sakit X Kabupaten Jember.Jurnal IKESMA.11(1). 
3.Mandriani.,E,dkk.(2018).Analisis

Dimensi Budaya Keselamatan Pasien Oleh

Petugas Kesehatan di RSUD dr Rasidin

Padang Tahun 2018.Jurnal Kesehatan Andalas.8(1).

4.Mudayana.,A.,A,.(2014).Peran Aspek

Tenaga Medis Dalam Penerapan Budaya

Keselamatan Pasien Di Rumah

Sakit.Suplemen Majalah Kedokteran Andalas.37(1).

5.Najihah.(2018).Budaya Keselamatan

Pasien dan Insiden Keselamatan Pasien di

Rumah

Sakit.Journal

Of

IslamicNursing.3(1).

6. Neri, R. A., Lestari, Y., \& Yetti, H.(2018). Analisis Pelaksanaan Sasaran Keselamatan Pasien Di Rawat Inap Rumah

Sakit Umum Daerah Padang Pariaman. Jurnal Kesehatan Andalas, 7, 48-55.

7.Pujilestari.,A.,.dkk.(2014).Budaya

Keselamatan Pasien di Instalasi Rawat Inap RSUP DR.Wahidin Sudirohusodo Kota Makassar.Jurnal MKMI. 57-64.
8. Rivai, F., Sidin, A., I., \& Kartika, I. (2016). Faktor Yang Berhubungan Dengan Implementasi Keselamatan Pasien Di Rsud Ajjappannge Soppeng Tahun 2015. Jurnal Kebijakan Kesehatan Indonesia. 5(4), 152154.

9. Simamora, R. H., \&Fathi, A. (2019). The Influence Of Training Handover Based SBAR Communication For Improving Patients Safety. Indian journal of public health research \& development, 10(9), 1280-1285.

10. Yarnita.,Y., $\quad \&$ Maswarni,.(2019).Budaya Keselamatan Pasien Pada Perawat Di Instalasi Perawatan Intensive RSUD Arifin Achmad Provinsi Riau.Jurnal Keperawatan Priority.2(2).

11.Yasmi.,Y., \& \& Hasbullah.,T,.(2018).Faktor-Faktor Yang Berhubungan dengan Budaya Keselamatan Pasien di Rumah Sakit Karya Bhakti Pratiwi Bogor tahun 2015.Jurnal ARSI.4(2). 